\title{
El poder de la auctoritas dramática: Francisco de Rojas Zorrilla frente a la comedia bizantina ${ }^{\top}$
}

\section{The Power of the Dramatic Auctoritas: Francisco de Rojas Zorrilla in front of the Byzantine Comedy}

\section{Julián González-Barrera}

Universidad de Sevilla

ESPAÑA

jgonbar@us.es

[Hipogrifo, (issn: 2328-1308), Volumen extraordinario, 1, 2018, pp. 37-55]

Recibido: 08-05-2017 / Aceptado: 19-05-2017

DOI: http://dx.doi.org/10.13035/H.2018.extra01.05

Resumen. Francisco de Rojas Zorrilla fue uno de los poetas favoritos de la corte a principios del siglo XVII, incluso por encima de Calderón de la Barca. Aquel favor real le permitió una libertad creativa que le llevó a experimentar con nuevos métodos, géneros y motivos. Tal fue el caso de su Persiles y Sigismunda, que no solo fue una simple adaptación de la novela cervantina, sino un intento de superar el modelo que Lope de Vega había creado para la comedia bizantina, aportando nuevas formas a un género que se creía cerrado.

Palabras clave. Francisco de Rojas Zorrilla; comedia bizantina; Lope de Vega; tragedia.

Abstract. Francisco de Rojas Zorrilla was one of the poets most favoured by the Court, even more than Calderón de la Barca. That royal favour gave him a creative freedom that lead to experiment with new methods, genres and motifs. That was

1. Este trabajo se enmarca en el proyecto FFI2014-52007-P, «Autoridad y poder en el teatro del Siglo de Oro. Estrategias, géneros, imágenes en la primera globalización», Ministerio de Economía y Competitividad, Gobierno de España. Dirección General de Investigación Científica y Técnica. Programa Estatal de Fomento de la Investigación Científica y Técnica de Excelencia. 
the case of Persiles and Sigismunda, not only a mere adaptation of the cervantine novel, but also an attempt to surpass the model that Lope de Vega had created for the byzantine comedy, adding new formulas to a genre considered closed.

Keywords. Francisco de Rojas Zorrilla; Byzantine Comedy; Lope de Vega; Tragedy.

Si bien aún se pueden leer voces que parecen relativizar la propia existencia del subgénero bizantino ${ }^{2}$, la acumulación de pruebas, ejemplos y evidencias comenzaría a ser abrumadora. No solo a lo largo de la vasta producción dramática de Lope de Vega, sino también en otros autores, obras y pasajes del teatro barroco español. Tal sería el caso, por ejemplo, de Francisco de Rojas Zorrilla (1607-1648)3, que incluso se habría preocupado de llevar una novela bizantina a las tablas: Los trabajos de Persiles y Sigismunda de Miguel de Cervantes, refrendando una metamorfosis de género que todavía hoy algunos pretenden negar. Sin embargo, lo verdaderamente interesante sería la manera en la que el poeta toledano afrontó la adaptación dramática, pues, aunque respetó las principales coordenadas teatrales - establecidas anteriormente por el Fénix ${ }^{4}$-, intentó separarse del magisterio de sus predecesores dando una vuelta de tuerca al género, aprovechando la mutabilidad de la Comedia Nueva; por ejemplo, para prescindir del tradicional final feliz en favor de un desenlace más trágico:

A medida que me he ido internando en estos géneros he podido comprobar la relevancia para el historiador del teatro de formaciones más pequeñas que los géneros, de agrupaciones de obras que aparecen en un momento dado de la obra de Lope o de sus contemporáneos y que luego desaparecen o no, de redes de piezas que exploran un determinado conflicto y las posibles respuestas al mismo, por debajo incluso de los géneros [...] Podríamos denominarlos provisionalmente subgéneros o sotogéneros ${ }^{5}$.

A las claras, no seríamos los primeros en abrir esta puerta. Ya otros llamaron la atención sobre una comedia de Rojas Zorrilla cuyo simple título acreditaría una herencia bizantina: Persiles y Sigismunda $(1632-1633)^{6}$. Una pieza teatral que tuvo que brillar con fuerza el día de su estreno para luego apagarse con la misma fogosidad?

No parecía una elección al azar. Sin ir más lejos, la novela cervantina había cosechado hasta diez ediciones entre la salida a imprenta y el lanzamiento de su adaptación dramática ${ }^{8}$; es decir, Rojas Zorrilla estaba trasladando a los escenarios un auténtico éxito de ventas, una hipotética garantía vista la magnitud del

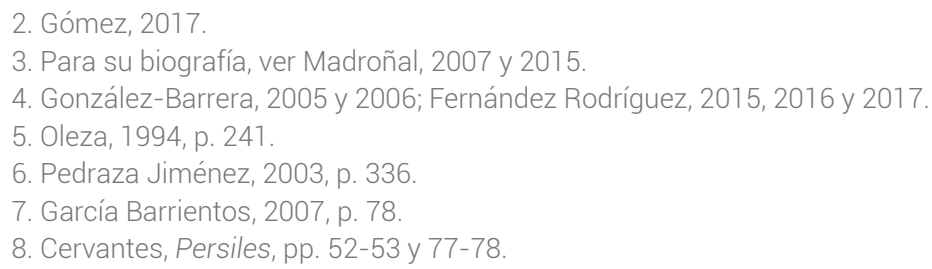


envite. Persiles y Sigismunda se estrenaría ante los Reyes de España en el Palacio del Pardo un 23 de febrero de 1633, por la compañía de Luis López de Sustaete. Luego prácticamente nada ${ }^{9}$, aunque consta que pasaría pronto a Italia, donde sería traducida por Marco Napolioni ${ }^{10}$. En cambio, su fortuna editorial fue algo más esclarecida: se publica por primera vez en la Parte veinte y nueve de doce comedias famosas de varios autores (Valencia, 1636), para reimprimirse antes de acabar el año en la Parte treynta de la misma colección (Zaragoza, 1636). Con el cambio de década aparecerá recopilada con otras del mismo autor en la Primera parte de las comedias de don Francisco de Rojas Zorrilla (1640). Ya fallecido el dramaturgo, solo nos consta una segunda edición de la Primera parte (1680) y una suelta sin pie de imprenta ${ }^{11}$, amén de un manuscrito con una censura fechada el 20 de noviembre de 1674, a cargo de Francisco de Avellaneda ${ }^{12}$.

Uno de aquellos «pájaros nuevos» que Lope trataba con desdén, Rojas Zorrilla fue el dominador de la escena cortesana durante el segundo cuarto del siglo XVII, por encima incluso del propio Calderón ${ }^{13}$. Favorito de palacio, el hecho de que una de sus primeras obras, como era aquella adaptación cervantina, se estrenara ante la Familia Real nos brinda la verdadera dimensión del personaje ${ }^{14}$. En líneas generales, Persiles y Sigismunda parece corroborar la opinión mayoritaria acerca del usus scribendi zorrillesco: «En esta comedia se abusa de efectismos y de crueldad exagerada, rasgos por los que ha sido censurado» ${ }^{15}$. Una dramatización hiperbólica que parece tener mayor presencia en sus obras trágicas, por cierto. Sobre el estilo tan afectado como extravagante del poeta toledano ya se ha escrito, examinado y reprendido harto, por lo que no descenderemos a la arena en este tema. No obstante, muy posiblemente aquella preferencia pretérita por sus tragedias en detrimento de sus comedias -justo al contrario de lo que sucede en nuestros días-, bien podría estar justificada en el gusto de la época por una práctica escénica tildada hoy de hiperdramática ${ }^{16}$; pero que bien podría haber sido la clave de su triunfo en palacio:

una pieza (Persiles y Sigismunda) que parece dirigirse a un público cortesano, leído y entendido, al que ofrece un texto con extensas acotaciones, que requiere

9. Ni García Lorenzo (2007) ni González Cañal (2015) recogen ninguna otra representación de Persiles y Sigismunda en sus exhaustivos inventarios. Esto no quiere decir que no pudiera haber sido reestrenada más veces, claro está.

10. Marcello, 2015, p. 160.

11. La suelta forma parte del fondo antiguo de la Biblioteca de la Universidad de Toronto (Thomas Fisher Rare Book, 917164).

12. Biblioteca Nacional de España, ms. 17062.

13. González Cañal, 2003, p. 1150.

14. Los estrenos palaciegos se sucederían en cascada a lo largo de todo el siglo XVII, antes y después de su muerte. Para un repertorio de títulos, ver González Cañal, 2015, pp. 139-144.

15. García Martín, 1980, p. 184

16. «El hiperdramatismo de sus tragedias, [...], es decir, [...] su inclinación exagerada por la sangre y por las situaciones desmesuradamente dramáticas. Asesinatos, homicidios, fratricidios, filicidios, infanticidios, suicidios, violaciones, incestos..., se alternan con un único fin: mover el ánimo de los oyentes» (Julio Giménez, 2000, pp. 180-181). 
cierto aparato escenográfico y tiene un sentido final trágico que no existe en la novela cervantina ${ }^{17}$

Acertada o no la etiqueta, lo cierto es que la dramaturgia de Rojas Zorrilla intentó marcar su propio sello en un momentum tan crítico como fue aquel interregno cómico que se produjo en la década de los años treinta.

\section{EL GÉNERO}

Acerca del género, la crítica moderna ha estado un tanto indecisa sobre cómo catalogar al Persiles zorrillesco. Así, por ejemplo, su última editora prefirió tildarla de «comedia trágica» ${ }^{18}$, pero Gómez Rubio se inclinaría por el rótulo de «tragedia palatina» ${ }^{19}$, aunque hacía una década que ya se habían divulgado los parámetros de la comedia bizantina. A nuestro juicio no harían falta rodeos, pues estaríamos ante una tragedia bizantina o cuanto menos una tragicomedia, en función del valor que le queramos dar a la presencia de un donaire tan inusual como Tarimón. Sobre el apellido del Persiles ya nos ocuparemos en el siguiente apartado. Ahora parece conveniente determinar la auténtica naturaleza de nuestra obra.

En el pasado, González Cañal aventuraba de forma implícita que nos enfrentábamos a una tragedia, no una comedia: «Rojas hace hincapié en la fatalidad que lleva finalmente a los protagonistas a la tragedia» ${ }^{20}$. El poeta toledano no respetaba el consabido final feliz de la prosa griega, reservando un final calamitoso para los enamorados y privándoles del justo premio a su intachable moral:

El final feliz es otro rasgo que delinea la novela bizantina; después de la azarosa sucesión de aventuras los amantes se reencuentran, se reconocen y se casan, quedando restablecida la armonía universal ${ }^{21}$.

Ya María Teresa Cattaneo había advertido del final tan desfigurado del Persiles de Rojas Zorrilla, muy alejado del desenlace cervantino ${ }^{22}$.

Para aclarar de una manera decisiva si nos hallamos ante una comedia o una tragedia, bastaría con poner sobre la mesa las diferencias principales entre unas y otras, tal y como se pueden colegir de las páginas de la Philosophía antigua poética (1596) de Alonso López Pinciano, donde el humanista vallisoletano enumera una larga lista:

- Eso deseo - dijo Ugo- que las oyáis, para que me respondáis a algunas dificultades que se me ofrezcan. Es la primera de las diferencias (que entre la tragedia y comedia se ponen) que la tragedia ha de tener graves personas y la comedia,

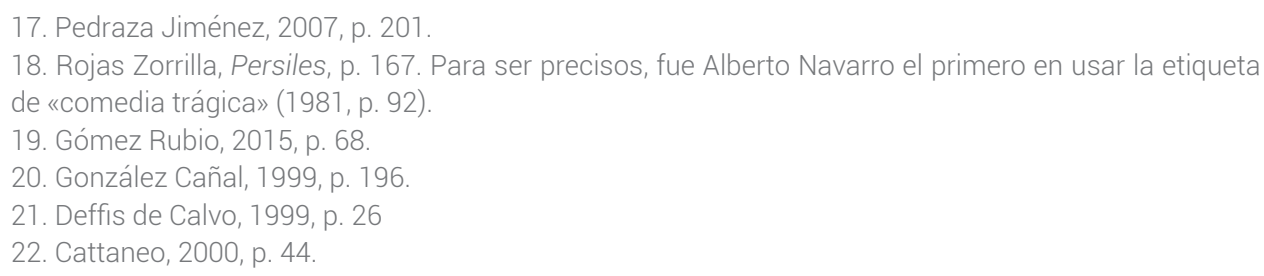


comunes. Y es la segunda que la tragedia tiene grandes temores llenos de peligro y la comedia, no. La tercera, la tragedia tiene tristes y lamentables fines, la comedia, no. La cuarta, en la tragedia, quietos principios y turbados fines, la comedia, al contrario. La quinta, que en la tragedia se enseña la vida que se debe huir y en la comedia la que se debe seguir. La sexta, que la tragedia se funda en historia y la comedia es toda fábula, de manera que ni aun el nombre es lícito poner de persona, como ya se dijo antes. La séptima, que la tragedia quiere y demanda estilo alto y la comedia, bajo. Y aun otras muchas más que no me acuerdo ${ }^{23}$.

La muerte de los protagonistas no sería concluyente para catalogar una pieza teatral como trágica, pero, si leemos con atención al Pinciano, sí que sería una conditio sine qua non para distinguir una tragedia de una comedia, concretamente la tercera. Dice así:

- Es la tercera, que la tragedia tiene tristes y lamentables fines, y la comedia alegres, la cual no sólo no contradice, mas confirma a mi diferencia y es también una con ella.

Ugo dijo entonces: -Pues las tragedias también suelen tener alegres fines.

Fadrique respondió: -Sí, mas no la comedia tristes jamás ${ }^{24}$.

Hasta siete son las desavenencias que se señalan en la Philosophía antigua poética, pero, en realidad, aparte de esta tercera, bastaría añadir la primera y la segunda para zanjar el debate. En la primera se advierte de que la tragedia debe estar regida por personajes de clase, rango y condición elevada:

Es la primera de las diferencias (que entre la tragedia y comedia se ponen) que la tragedia ha de tener graves personas y la comedia, comunes [...] porque las personas graves ríen poco, que el reírse mucho es de comunes ${ }^{25}$.

En nuestra obra, la acción camina sobre los hombros de reyes (Leopoldo), príncipes (Persiles) y princesas (Sigismunda e Isabela), dejando un protagonismo muy reducido a otros personajes de baja condición, como Tarimón o los bárbaros, ceñidos a su rol secundario. Para seguir reforzando nuestra tesis de trabajo, la tercera pata del banco sería otra divergencia clara entre géneros, a juicio del Pinciano:

Y es la segunda que la tragedia tiene grandes temores llenos de peligros y la comedia, no. [...] si la tragedia está llena de temores y peligros, no podrá criar pasatiempo y risa, sino lástima y compasión ${ }^{26}$.

Ciertamente, todo el Persiles está plagado de infortunios para los enamorados, que comienzan cautivos de unos salvajes bárbaros y terminan cayendo al vacío desde lo alto de una muralla. Sin olvidar grilletes, naufragios y raptos a sangre y fuego, por tierra y por mar. Un peligro de muerte que como aliento de Némesis ace-

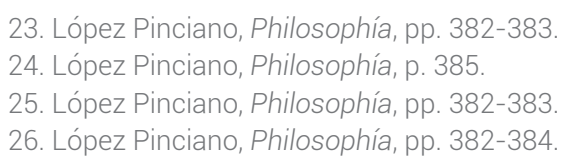


cha a la pareja protagonista, para finalmente abalanzarse sobre ellos de manera fulminante, aunque un tanto ridícula.

Asentados estos tres cimientos de lo que sería una verdadera tragedia bizantina, quedaría por dilucidar la importancia de aquella mezcla de lo trágico y lo cómico que blasonaba a la Comedia Nueva y que habitualmente quedaba en manos del gracioso. En realidad, aquí tenemos un donaire disminuido, sin gracia ni protagonismo, con un rol apenas trascendente, salvo acaso ser el responsable involuntario de la última desdicha de Persiles y Sigismunda y, por ende, el culpable indirecto de su muerte. A veces más preocupado en hacer metateatro que en hacer reír; en palabras de García Barrientos, «una presencia desangelada ${ }^{27}$. Ni siquiera acompaña al galán en sus desgracias, como era costumbre en el teatro barroco, sino que aparece y desaparece de la trama como lo haría cualquier otro personaje secundario. En nuestra opinión sería muy poco bagaje para hablar seriamente de tragicomedia: «Tarimón, el gracioso; cuya presencia, por cierto, constituye a mi juicio otra verdadera anomalía, ésta de género, en la dramaturgia de la pieza» ${ }^{28}$. A lo sumo, un gracioso interesante -ahí compartimos la opinión de Felipe Pedraza ${ }^{29}$-, pero tan nimio que a duras penas conseguiría elevar nuestra obra a la categoría de tragicomedia.

Por consiguiente, aun aceptando la posibilidad de una difícil taxonomía tragicómica, creemos más acertado considerar al Persiles como una tragedia bizantina, de las llamadas patéticas por Aristóteles ${ }^{30}$, explicadas por el genio de González de Salas: «La segunda, patética o afectuosa, en donde se representan tan horribles sucesos y lastimosos que mueven afectos y dolores singularmente» ${ }^{31}$.

\section{EL SUBGÉNERO}

En esta cuestión, el hecho de tratarse de una adaptación de la novela homónima de Cervantes debería haber evitado el debate, en nuestro modesto entender. Bien es cierto que la estructura alambicada de la materia bizantina era poco apta para los escenarios $^{32}$, pero el atractivo de aquellos largos viajes, cautiverios inmisericordes y extrañas tierras la hacía especialmente idónea para el gusto de los espectadores del siglo XVII. Un género capaz de enseñar una moralidad impecable dentro de los cánones de la Contrarreforma y al mismo tiempo deleitar al público con aventuras increíbles de imaginar. El propio Cervantes nos daría la razón a cuenta de su Persiles, cuando ironizaba sobre la posibilidad de componer una pieza teatral basada en los sucesos de Periandro y Auristela:

¡Válame Dios, y con cuánta facilidad discurre el ingenio de un poeta y se arroja a romper por mil imposibles! ¡Sobre cuán flacos cimientos levanta grandes qui-

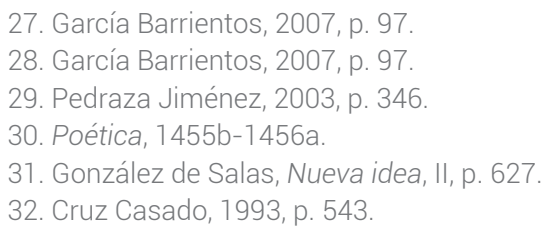


meras! Todo se lo halla hecho, todo fácil, todo llano [...] Allí se vio él en el mayor que en su vida se había visto, por venirle a la imaginación un grandísimo deseo de componer de todos ellos una comedia, pero no acertaba en qué nombre le pondría: si le llamaría comedia, o tragedia, o tragicomedia ${ }^{33}$.

Sin embargo, bien es cierto que el plan de Rojas Zorrilla parece ser no tanto seguir la fuente original, sino servirse de ciertos pasajes desperdigados para forjar un nuevo vehículo para el tema griego. En otras palabras, el poeta toledano intenta dar rienda suelta a uno de los principios que regían la mentalidad artística barroca: la emulación.

La strategia che Rojas segue nella parte più direttamente utilizzata del romanzo cervantino è evidente: selezionare un piccolo numero di situazioni adatte a colpire per la loro spettacolarità o per la loro intensità drammatica, mentre altre avventure vengono solo rievocate attraverso i dialoghi dei personaggi e altre vengono introdotte ex novo creando un nuovo contesto d'insieme ${ }^{34}$.

A todas luces, Rojas Zorrilla intenta experimentar con un subgénero como el bizantino que debía conocer bien. Como si se tratara de un acto de reivindicación, pretende superar con su modelo a todo lo escrito anteriormente, sea en prosa o verso, trasladando las formas, motivos y argumentos bizantinos al reino lastimoso de la tragedia. Por norma, Lope había respetado el final feliz de este tipo de historias, pero el poeta toledano tenía la intención de marcar distancias.

Por supuesto, que se trate de la adaptación de una novela barroca de peregrinos no puede ni debe ser el único motivo para tildar de bizantina a nuestra obra. Como veremos a continuación, se tratará de una concatenación de técnicas, artificios y motivos que se remontarían a Heliodoro, Aquiles Tacio y otros. A pesar de todo, teniendo en cuenta que precisamente será en aquel primer cuarto del Seiscientos cuando la prosa griega alcanzaría la cima de su relevancia ${ }^{35}$, esta metamorfosis de novela a teatro se trasluce como otra consecuencia natural del momento barroco:

The evolution of drama and novelistic prose in Spain offered seventeenthcentury writers an unrestricted territory in which genres could interact in close association. The demarcation between fiction and drama was sufficiently loose to encourage reciprocity. One of the least creative consequences of this flexibility was the largescale conversion of novels into drama ${ }^{36}$.

Para llevar a cabo nuestro intento de clasificar al Persiles zorrillesco vamos a echar mano de otros paradigmas del subgénero bizantino, en concreto: Viuda, casada y doncella; Los tres diamantes; La doncella Teodor, ya definidos en el pasa-

33. Cervantes, Persiles, p. 443.

34. Scaramuzza Vidoni, 2000, p. 205

35. «La irrupción del Persiles, con numerosas ediciones entre 1617 y 1630, una nueva edición de Heliodoro (1616) y la aparición de la primera versión completa de la novela de Aquiles Tacio (1617) son las manifestaciones más destacadas del éxito del género en España» (González Rovira, 1996, p. 249). 36. Yudin, 1969, p. 587 
do ${ }^{37}$, amén de Los trabajos de Persiles y Sigismunda, para establecer un cuadro comparativo que nos posibilite una mejor aproximación a las verdaderas coordenadas de nuestra obra (ver Tabla final).

\section{TÉCNICAS Y ARTIFICIOS}

La primera de las técnicas bizantinas que trascenderá a los versos será el principio in medias res, santo y seña del género desde Heliodoro: abrir la narración en mitad de la historia para provocar el asombro y la inmediata inmersión del lector. Un recurso que había aupado al obispo de Emesa a la par de Homero y Virgilio, según afirmaba un entusiasta López Pinciano:

Heliodoro guardó eso más que ningún otro poeta, porque Homero no lo guardó con ese rigor, a lo menos en la llíada, ni aun en la Ulysea si bien se mira; y, si miramos a Virgilio, tampoco comenzó del medio ${ }^{38}$.

En la adaptación zorrillesca, según la acotación de inicio, Persiles y Sigismunda salen a escena con los ojos vendados y las manos atadas a la espalda, a merced de unos salvajes bárbaros dispuestos a sacrificarlos, sin que sepamos el porqué, el cómo ni el dónde:

bajen todas las mujeres con flechas y arcos, y detrás de ellas, Sigismunda, en traje de hombre con los ojos vendados y las manos atadas a las espaldas; y por otro lado del monte, bajen Bradamiro, con barba roja, vestido de pieles, Corsicurvo y dos bárbaros, y detrás de ellos, Persiles, vestido pobremente, los ojos vendados, las manos ligadas atrás; y en bajando, los ate Corsicurvo ${ }^{39}$.

En este caso, como ya ocurriera en el original cervantino, recogemos un uso paradigmático del in medias res, porque se trataría de comenzar en mitad de la historia para luego, hacia la mitad, rehabilitar el ordo naturalis mediante una secuencia de analepsis completiva. Ambos muchachos relatan al rey Leopoldo todas sus aventuras hasta llegar a aquella isla de bárbaros e incluso más allá (vv. 2261-2534). Al final, la deuda con el vulgo queda saldada con un guiño metateatral: «lo demás, ya tú lo viste» (v. 2534).

No era esta la costumbre. A decir verdad, probablemente para simplificar aquellas tramas superlativas, la mayoría de los dramaturgos barrocos prefirieron una sucesión desordenada de los acontecimientos u ordo artificialis antes que recurrir al principio in medias res ${ }^{40}$, que podía confundir y, por lo tanto, irritar a un público

37. González-Barrera, 2005 y 2006.

38. López Pinciano, Philosophía, pp. 482-483.

39. Rojas Zorrilla, Persiles, p. 195.

40. Desde un punto de vista retórico, habría que precisar que en más de una ocasión se ha hablado de ordo artificialis y in medias res como si fueran prácticamente sinónimos - ver la Poética de Luzán, por ejemplo-, porque bien es cierto que ambos recursos alteran el orden natural del relato. Sin embargo, existen diferencias palpables que no explicaremos aquí, pero que se podrían resumir en que solo el principio in medias res exige enmienda antes de la conclusión. 
tan desapacible como el que abarrotaba los corrales de comedias. Así la mayoría de las veces, como sucederá en La doncella Teodor o Viuda, casada y doncella, el poeta se limita a abrir con un comienzo ex abrupto, apropiado también para captar la atención en un teatro sin telón de boca ${ }^{41}$.

La suspensión era otro de los artificios de la prosa griega que se pueden contemplar tanto en nuestra obra como en su fuente cervantina. Nos referimos a la intriga creada en el ánimo del destinatario por medio de un corte brusco en el devenir de los acontecimientos, cambiando la acción de tiempo y lugar. Por lo tanto, el espectador no sabe, solo presiente lo que ha sucedido con los personajes. Un golpe de efecto ideado para potenciar la admiratio del receptor:

un recurso que adquiere una dimensión psicológica al atender a las reacciones del lector, quien parece encontrarse ligado a la narración por el interés de conocer y resolver sus dudas, lo que repercute también en la excitación de sus facultades imaginativas $^{42}$.

Un recurso muy valorado por los preceptistas del Siglo de Oro que también acabaría trasvasándose a otros géneros, como la materia caballeresca y los romanzi. En el Cisne de Apolo (1602), Luis Alfonso de Carvallo lo recomendaba incluso de manera general para cualquier comedia:

En la epítasis, que es la segunda parte, como existencia de la comedia, hanse de proseguir la materia con diferentes sucesos de los que se pudieran pensar y otros varios y revueltos casos, como haciendo ñudos, procurando tener siempre el ánimo de los oyentes suspenso, ya alegres, ya tristes, ya admirados, y con deseo de saber el fin de los sucesos, porque cuanto esta suspensión y deseo fuere mayor, le será más agradable después el fin, por serlo siempre lo que es más deseado ${ }^{43}$.

En la tragedia de Rojas Zorrilla, uno de los momentos de mayor suspense llegará al final del primer acto, cuando el viento arrastra mar adentro a la barca que lleva a Sigismunda, dejando a su desconsolado amante en la orilla, rodeado de grandes llamas. A continuación, el segundo acto se abrirá con una escena entre una pareja de personajes nuevos: el rey Leopoldo y la infanta Isabela, por lo que nada sabemos del paradero de los enamorados.

La suspensión y admiración del espectador se acentúa con el remate de las distintas jornadas a través de una serie de cláusulas paralelas en las que cada personaje va expresando sus sentimientos ante su inmediata separación ${ }^{44}$.

En las comedias bizantinas es harto frecuente hallar semejante pathos, pues el poeta gustará de manipular los nervios del público. Un efecto desestabilizador que se podía multiplicar si se recurría a la doble focalización, es decir, a dividir la trama en dos acciones separadas con cada joven como protagonista. Se trataba

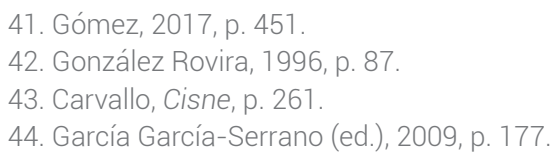


de aprovechar aquellas continuas separaciones para manejar la incertidumbre de los espectadores. Caso paradigmático es La doncella Teodor, donde la joven y hermosa Teodor termina el segundo acto dispuesta a suicidarse, concluyendo todo sin que sepamos el desenlace, pues el tercer acto se iniciará retomando la historia del galán.

La anagnórisis era otra de las técnicas utilizadas por la prosa griega para provocar la sorpresa del lector. En realidad se trataría de una herramienta heredada de la tragedia clásica que los modelos de Heliodoro y Aquiles Tacio exportaron a otros géneros narrativos, donde se llegó a usar con denuedo, como en los libros de caballerías o la novela corta italiana. El reconocimiento o descubrimiento de las identidades de algunos personajes en momentos puntuales de la acción, especialmente al final de la obra, otorgaba una oportunidad excelente para causar la admiratio, más si cabe cuando el lector no había sido puesto sobre aviso. El teatro del Siglo de Oro no fue ajeno a este recurso, que además servía para reconocer a inocentes y culpables ${ }^{45}$. Era frecuente que apareciera en tramas donde se usara el disfraz, bien para esconder la identidad, bien para ocultar el sexo, sobre todo en la mujer vestida de hombre, tan del gusto de la época. En el primer acto del Persiles de Rojas Zorrilla, los jóvenes enamorados tardan en reconocerse a pesar de estar uno frente al otro:

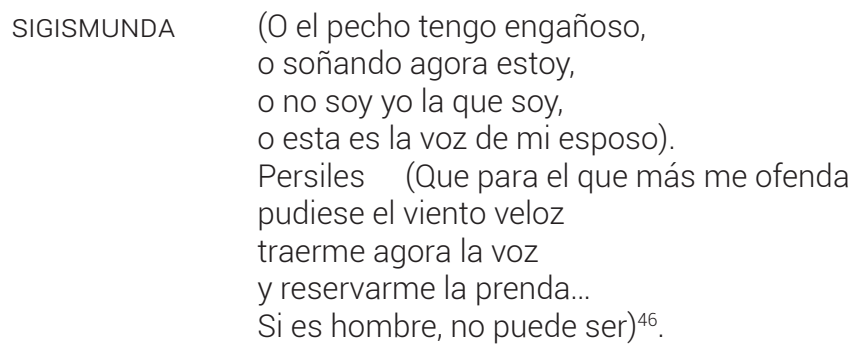

A la postre, se trataría de una confusión bien llevada gracias a la complicidad del espectador, que sabe o sospecha en todo momento quiénes son en realidad.

\section{MOTIVOS Y ARGUMENTOS}

Entre los motivos que suele generar una novela bizantina existe uno que destacaría por encima de todos: la defensa de la castidad. Virtud de estimación sobresaliente en el cristianismo, especialmente vinculada a la honra de la mujer en las sociedades católicas, la castidad se convertirá en uno de los patrones narrativos más recurrentes en la prosa de Heliodoro y sus sucesores. En el Barroco se ensalzará aún más su valor, siendo en ocasiones el motor de la huida, pues el voto de castidad suele erigirse como el requisito obligado para que ella acceda a escaparse con él. Bastaría recordar el conocido juramento con el que Nise obligó a Pánfilo en El peregrino en su patria (1604): «dondequiera que él quisiese le seguiría, con tal 
condición que le hiciese un solemne juramento de no gozarla menos que estando casado con ella» ${ }^{47}$.

Como ocurriera en la novela, Rojas Zorrilla repite el voto de castidad de Sigismunda ligado a su promesa de peregrinación a Roma. Durante la analepsis completiva antes referida, Persiles relata al rey Leopoldo el voto hecho por su amada al que él se siente irremediablemente atado:

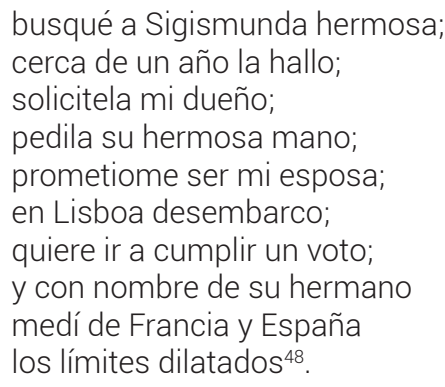

Para salvaguardar su valiosísima castidad y, por consiguiente, la consecución última de su promesa de matrimonio, aquellos peregrinos de amor perpetrarán toda clase de engaños, artimañas y falacias para sujetar a sus pretendientes. Estratagemas donde normalmente ella tenga la iniciativa, siguiendo las convenciones del género griego ${ }^{49}$. Unas argucias que bien podrían dañar la moralidad inmaculada de los protagonistas, pero que frecuentemente son disculpadas o dispuestas para la justicia divina:

$\begin{array}{ll}\text { PERSILES } & \text { Digo, pues, que yo he fingido } \\ \text { que por Isabela vengo } \\ \text { con intento de librarte } \\ \text { si quiere ampararme el cielo }{ }^{50}\end{array}$

Como ejemplo de esta defensa a ultranza de la virginidad adviértase que tanto en el Persiles narrativo como dramático los protagonistas fingen ser hermanos. Un recurso manido que se remontaría a los modelos de auctoritas, donde se emplearía para hacer gala de aquella castidad de puertas para afuera, pero también de puertas para adentro:

Hay, en fin, un motivo que ya aparece en Aquiles Tacio y que desarrollará ampliamente Heliodoro, que es el de la falsa hermandad de los protagonistas y que creemos que tiene relación con este hecho. Y es que el que Teágenes y Cariclea pasen por hermanos no es, en nuestra opinión, solo un engaño ante los posibles agresores; puede ser también un modo de mostrar implícitamente esa relación 
asexuada que mantienen en el curso de todas sus peripecias ambos protagonis$\operatorname{tas}^{51}$.

No sería el único engaño. Si volvemos la vista al teatro barroco, en La doncella Teodor don Félix dilata un casamiento indeseable con la excusa de una supuesta conjunción lunar; y en Viuda, casada, doncella, nuestra protagonista decide guardar el luto por su amado Feliciano como si verdaderamente hubieran estado casados.

El matrimonio concertado en contra del deseo filial es otro de los elementos prácticamente omnipresentes en toda trama bizantina. Desde Heliodoro en adelante, el fuego del conflicto aparece alimentado por una dialéctica provocadora entre la autoridad paterna y el libre albedrío de los jóvenes, que en más de una ocasión será el verdadero detonante de la peregrinatio amoris. Un argumento, por otra parte, que tendría su origen en la comedia latina y que había envejecido con buena salud en España a través de la Armelina de Lope de Rueda.

Sobre las tablas, el poeta toledano plantea la doble pareja arquetípica en la Comedia Nueva, institucionalizada por el Fénix, donde tanto Persiles -infanta Isabela- como Sigismunda - rey Leopoldo- rehúsan las nupcias orquestadas por sus respectivos padres, aunque juegan con las esperanzas de sus pretendientes para ganar tiempo e idear un plan de huida. Algo muy similar, por ejemplo, a lo que Lope disponía para otra comedia bizantina: La doncella Teodor. El galán, don Félix, decide secuestrar a Teodor en el camino a sus bodas con un viejo catedrático. El rechazo al matrimonio concertado se interpretaba como un desafío al orden social establecido:

Es un sistema de trasgresión, sanción y retribución, propio de la novela corta, elaborado para defender la institución del matrimonio, reformado en profundidad durante el Concilio de Trento. Sin embargo, a diferencia del género corto, donde encontramos una alternancia entre desenlaces trágicos y conclusiones dichosas, en las novelas bizantinas siempre hay un final feliz ${ }^{52}$.

La particularidad estriba de nuevo en la dramaturgia de Rojas Zorrilla, que deriva el final hacia los parámetros de la novela corta, más adaptada a los finales trágicos, especialmente si estaban provocados por el accidente o la confusión. En contra de las directrices del género bizantino, el celo, vigilancia y observancia moral de los jóvenes enamorados no encontrará recompensa, como sucederá en cambio en el original cervantino.

Vinculado al artificio de la suspensión aparece el motivo de la falsa muerte de uno de los protagonistas, que sumerge la trama en una espiral anfibológica que puede ser completa, cuando ni público ni personajes conocen la verdad, o incompleta, cuando solo uno de los dos ha quedado descabalgado de la acción. Bajo la égida de Heliodoro y Aquiles Tacio, que lo emplearon con audacia para sembrar la desesperación, los ingenios barrocos se valieron de un recurso dirigido a aumen-

51. Brioso Sánchez, 2002, p. 215

52. González-Barrera, 2005, p. 85.

HIPOGRIFO, Volumen extraordinario, 1, 2018 (pp. 37-55) 
tar la tensión dramática, sobre todo cuando el público desconocía la fortuna o el paradero de los enamorados. En Viuda, casada y doncella, por ejemplo, llegan a Valencia los rumores de la muerte de Feliciano y, en Los tres diamantes, la familia de Lisardo acusa a Enrique de Inglaterra de ser su asesino. Será especialmente emocionante en La doncella Teodor, en el episodio antes referido, cuando al final del segundo acto Teodor decide suicidarse arrojándose al mar. Tardaremos mucho tiempo en saber qué fue de ella:

[TEODOR] Entre tanto, quejas tristes id a Felis, decilde que fue traidor y yo mujer y firme ${ }^{53}$.

En Los trabajos de Persiles y Sigismunda, Cervantes apenas se hace eco de este truco de ilusionista, salvo en el fallecimiento aparente de Periandro, tras su caída de la torre. Si dirigimos nuestra atención hacia la adaptación de Rojas Zorrilla no hallamos ningún suceso de falsa muerte como tal, probablemente porque el poeta toledano era consciente de que estrenaba ante un público cortesano culto, que muy bien podía conocer o incluso haber leído el libro. Sin olvidar que, teniendo en la cabeza un final tan trágico como inesperado, no se debía lanzar el anzuelo de una falsa muerte a medio camino porque podría caer en la trampa del cuento del pastorcillo y el lobo. Escarmentados por una falsa noticia anterior, podría ser que los espectadores se quedaran incrédulos cuando llegara la verdadera muerte de los enamorados. Un preaviso que desbarataría el efecto dramático de la última escena.

Otro de los motivos recurrentes en toda trama bizantina es la presencia del mar como un medio para el conocimiento de uno mismo, lleno de peligros y siempre impredecible. Una metáfora de la vida humana que los protagonistas deberán atravesar juntos o por separado. En la novela barroca de peregrinos suele erigirse como un paso de purificación tanto física como moral, porque los enamorados no solo deberán proteger sus vidas, sino también su religión y castidad. Desde sus principios, el mar ha estado muy presente en este género dada la importancia que tenía en la Antigüedad, especialmente en el ámbito mediterráneo. De hecho, tanto Aquiles Tacio como Helidoro se detuvieron con detalle en la descripción de aquellas largas travesías marítimas hasta el punto de llamar la atención de los historiadores, que tomaron los textos como auténticas cartas de navegación:

Aquiles Tacio y Heliodoro son los únicos que nos describen con algunos pormenores uno de estos viajes por mar, el primero una travesía entre Berito (Beirut) y Egipto, que precisamente ha sido estudiada por Rougé por el interés y el rigor de sus datos; y Heliodoro, en un entrecortado y mucho menos detallado relato en boca del sacerdote Calasiris, la accidentada navegación entre Delfos e igualmente Egipto $^{54}$. 
En el subgénero bizantino y, por supuesto, en la adaptación de Rojas Zorrilla se convertirá en un elemento estructurador de la acción, capaz de decidir el destino de la pareja como si se tratara de un personaje más:

PERSILES Sigismunda ya se aleja.

Ya no responde a mis voces.

¡Ay dolor! Olas soberbias,

pues nos apartáis las almas,

dejad las voces siquiera ${ }^{55}$.

Asociado al escenario del mar surgen los motivos de la tormenta y, como consecuencia natural de esta, el naufragio. Tanto en prosa como en teatro, la furia de las olas se configura como un poderoso instrumento divisorio, pues igual puede separar a los jóvenes como arrastrarlos a lugares todavía más misteriosos, apartados y remotos. La historia gana en atractivo gracias a la incertidumbre que aporta, aunque bien es sabido por todos que los protagonistas demostrarán una y otra vez un talento insólito para sobrevivir a cualquier borrasca. En el Persiles de Rojas Zorrilla, el viaje a través de regiones exóticas como la isla de Tile o el reino de Dalmacia, muy lejos del imaginario del español del siglo XVII, se ve continuamente amenazado por violentas fortunas -italianismo de la época- que desbaratan o retrasan sus propósitos. Como agente de la acción dramática, el autor puede desarrollar tempestades como pretexto para distanciar a los protagonistas (Persiles), dar por muerto a uno de ellos (Viuda, casada y doncella) o como barrera insalvable de sus deseos (La doncella Teodor) ${ }^{56}$.

$\begin{array}{ll}\text { [PERSILES] } & \text { olas y sombras se encuentran; } \\ & \text { y tanto se levantaron } \\ & \text { desde el abismo las aguas } \\ & \text { que, chocando en los palacios } \\ & \text { de las regiones del fuego, } \\ & \text { presumo que la apagaron; } \\ & \text { acuchíllanse los vientos, } \\ & \text { cae la vela, cruje el árbol, } \\ & \text { la nave es pez, el mar cielo, [...] } \\ & \text { desencájase la quilla, } \\ & \text { y nuestro mísero vaso } \\ & \text { chupa salobres espumas } \\ & \text { al cristalino océano }{ }^{57} \text {. }\end{array}$

Ya desde tiempos de Heliodoro, una de las aventuras más populares del género bizantino sería el rapto de los protagonistas. Un episodio especialmente delicado para ellas, puesto que además deberán enfrentarse a la violencia sexual de sus captores. La virginidad prematrimonial adquiere una sacralidad inquebrantable, como era de esperar, en el caso de las heroínas. Paradigmática es la novela de 
Aquiles Tacio, donde se insinúa que Leucipa perdió algo más que la libertad cuando cayó en manos de los piratas, pero Clitofonte saldrá en su defensa después de la ordalía:

Y el elogio por el hecho de que, a pesar de haber elegido yo escaparme con ella, no haya consumado el motivo de tal fuga, no debe dirigírseme a mí, sino a ella, por haber permanecido virgen en medio de piratas y haber triunfado sobre el pirata peor: Tersandro, el sujeto más desvergonzado y brutal ${ }^{58}$.

A imitación de Leucipa, Rojas Zorrilla dispone que Sigismunda sea apresada durante su travesía, en este particular por unos cosarios ingleses, que no abusan de ella sexualmente, pero la venden como esclava a unos bárbaros para que pueda ser sacrificada:

$\begin{array}{ll}\text { [SIGISMUNDA] } & \text { y la diosa de la noche } \\ & \text { iba descogiendo el manto, } \\ & \text { cuando me cerca una nave } \\ & \text { de dos ingleses cosarios, } \\ & \text { y a la cámara de popa } \\ & \text { me trasladan desde el barco. } \\ & {[. . .]} \\ & \text { vendiéronme en un isla } \\ & \text { a precio de oro y, dejando } \\ & \text { a unos bárbaros mi vida }{ }^{59} .\end{array}$

Una pérdida de la libertad casi inevitable, porque relacionado con el motivo del rapto hallamos el tema del cautiverio en tierras salvajes, exóticas y remotas. Lugares que excitaban la imaginación de los lectores o espectadores. En el Persiles de Rojas Zorrilla los protagonistas recorren Europa desde el brumoso norte al cálido Mediterráneo, cayendo prisioneros en más de una ocasión. En los modelos clásicos, el cautiverio se convierte en uno de los desafíos más duros que afrontarán los jóvenes enamorados. Asediados por la porfía de lascivos pretendientes, deberán defender su castidad con ingenio, valentía y decisión. En la Antigüedad, Heliodoro había sentado cátedra con la esclavitud de Teágenes en Menfis y Aquiles Tacio con la de Leucipe en Éfeso. En el caso de nuestra obra, el poeta toledano echa mano de este argumento sin disimulo, pues Sigismunda sufre toda clase de prisiones, pasando de manos de cosarios a bárbaros y de bárbaros a reyes.

Otro de los peligros del cautiverio que acechaba a los amantes como espada de Damocles no estará relacionado con la pérdida de la libertad, sino con la religión. La apostasía era una amenaza cierta, sobre todo en la novela barroca de peregrinos, que incorpora este conflicto como la literaturización de una problemática real en el Seiscientos, como eran los cautivos cristianos del norte de África que en buen número optaban por abrazar el Islam para escapar de los grilletes. En este particular, en el Persiles no tenemos ese conflicto sobre las tablas, pues la ruta de los jóvenes 
enamorados seguirá otros derroteros lejos del mundo musulmán, pero sí es cierto que está muy presente en otras obras del subgénero bizantino, como La doncella Teodor o Los esclavos libres.

En conclusión, aunque se podrían aportar más motivos a nuestro estudio, preferimos cerrar aquí el argumentario para no dilatar más la cuestión. Creemos que existirían pruebas suficientes para describir al Persiles y Sigismunda de Rojas Zorrilla como un intento de emancipación de la auctoritas dramática de Lope, derivando el género bizantino hacia la tragedia, pero sin renunciar a las técnicas, artificios y motivos característicos de la prosa griega. A la sazón, una tragedia bizantina. Un paradigma más de la emulatio barroca, que obligaba a los ingenios áureos a imitar a los clásicos con el fin último de superarlos. Si lo consiguió o no, es otra historia. vale.

TABLA

\begin{tabular}{|l|l|l|l|l|l|}
\hline $\begin{array}{c}\text { Comedias } \\
\text { Motivos }\end{array}$ & $\begin{array}{l}\text { Viuda, } \\
\text { casada } \\
\text { doncella }\end{array}$ & $\begin{array}{l}\text { Los tres } \\
\text { diamantes }\end{array}$ & $\begin{array}{l}\text { La doncella } \\
\text { Teodor }\end{array}$ & $\begin{array}{l}\text { Persiles y } \\
\text { Sigismunda } \\
\text { (Cervantes) }\end{array}$ & $\begin{array}{l}\text { Persiles y } \\
\text { Sigismunda } \\
\text { (Rojas Zorrilla) }\end{array}$ \\
\hline $\begin{array}{l}\text { Defensa de la } \\
\text { Castidad }\end{array}$ & $\mathrm{X}$ & $\mathrm{X}$ & $\mathrm{X}$ & $\mathrm{X}$ & $\mathrm{X}$ \\
\hline $\begin{array}{l}\text { Matrimonio } \\
\text { concertado }\end{array}$ & $\mathrm{X}$ & $\mathrm{X}$ & $\mathrm{X}$ & $\mathrm{X}$ & $\mathrm{X}$ \\
\hline Falsa muerte & $\mathrm{X}$ & $\mathrm{X}$ & $\mathrm{X}$ & $\mathrm{X}$ & - \\
\hline Mar & $\mathrm{X}$ & $\mathrm{X}$ & $\mathrm{X}$ & $\mathrm{X}$ & $\mathrm{X}$ \\
\hline Tormenta & $\mathrm{X}$ & $\mathrm{X}$ & $\mathrm{X}$ & $\mathrm{X}$ & $\mathrm{X}$ \\
\hline Naufragio & $\mathrm{X}$ & $\mathrm{X}$ & $\mathrm{X}$ & $\mathrm{X}$ & $\mathrm{X}$ \\
\hline Rapto & $\mathrm{X}$ & $\mathrm{X}$ & $\mathrm{X}$ & $\mathrm{X}$ & $\mathrm{X}$ \\
\hline Cautiverio & $\mathrm{X}$ & $\mathrm{X}$ & $\mathrm{X}$ & $\mathrm{X}$ & $\mathrm{X}$ \\
\hline
\end{tabular}

\section{BIBLIOGRAFÍA}

Aquiles Tacio, Leucipa y Clitofonte, trad. Máximo Brioso y Emilio Crespo, Madrid, Gredos, 1997.

Brioso Sánchez, Máximo, «El viaje en la novela griega antigua», en Estudios sobre el viaje en la literatura de la Grecia antigua, ed. Máximo Brioso y Antonio Villarrubia, Sevilla, Universidad de Sevilla, 2002, pp. 185-262.

Carvallo, Luis Alfonso de, Cisne de Apolo, ed. Alberto Porqueras Mayo, Kassel, Reichenberger, 1997.

Cattaneo, María Teresa, «Los desenlaces en el teatro de Rojas Zorrilla», en Francisco de Rojas Zorrilla, poeta dramático. Actas de las XXII Jornadas de Teatro 
Clásico, ed. Felipe Pedraza, Rafael González y Elena Marcello, Almagro, Universidad de Castilla-La Mancha, 2000, pp. 39-54.

Cervantes Saavedra, Miguel de, Los trabajos de Persiles y Sigismunda, ed. Carlos Romero Muñoz, Madrid, Cátedra, 1997.

Cruz Casado, Antonio, «Persiles y Sigismunda. De Cervantes a Rojas Zorrilla», en Actas del Tercer Coloquio Internacional de la Asociación de Cervantistas. Alcalá de Henare, Madrid, Ministerio de Asuntos Exteriores-Anthropos, 1993, pp. 541-551.

Deffis de Calvo, Emilia I., Viajeros, peregrinos y enamorados. La novela española de peregrinación del siglo XVII, Pamplona, EUNSA, 1999.

Fernández Rodríguez, Daniel, «Las técnicas y artificios de la novela griega y las comedias bizantinas de Lope», en Venia docendi. Actas del IV Congreso Internacional Jóvenes Investigadores Siglo de Oro (JISO 2014), ed. Carlos Mata Induráin y Ana Zúñiga Lacruz, Pamplona, Servicio de Publicaciones de la Universidad de Navarra, 2015, pp. 61-71.

Fernández Rodríguez, Daniel, «Lope de Vega, el género bizantino y Los esclavos libres», Artifara, 16, 2016, pp. 147-164.

Fernández Rodríguez, Daniel, «Las comedias bizantinas de Lope en su contexto teatral español e italiano», Anuario Lope de Vega. Texto, literatura, cultura, 23, 2017, pp. 79-101.

García Barrientos, José Luis, «De novela a comedia: Persiles y Segismunda de Rojas Zorrilla», Revista de literatura, 69, 137, 2007, pp. 75-107.

García Lorenzo, Luciano, «De la fortuna escénica de Rojas Zorrilla en los teatros de Madrid», Revista de literatura, 69, 137, 2007, pp. 235-247.

García Martín, Manuel, Cervantes y la comedia española en el siglo XVII, Salamanca, Universidad de Salamanca, 1980.

Gómez, Jesús, «El artificio griego en Lope de Vega: narrativa y teatro», Anuario Lope de Vega. Texto, literatura, cultura, 23, 2017, pp. 441-460.

Gómez Rubio, Gemma, «Tragedias», en El universo dramático de Rojas Zorrilla, ed. Rafael González Cañal, Valladolid, Universidad de Valladolid, 2015, pp. 67-78.

González-Barrera, Julián, «La novela bizantina española y la comedia La doncella Teodor de Lope de Vega. Primera aproximación hacia un nuevo subgénero dramático», Quaderni Ibero-americani, 97, 2005, pp. 76-93.

González-Barrera, Julián, «La influencia de la novela griega en el teatro de Lope de Vega. Paradigmas para la configuración de un nuevo subgénero dramático», Anuario Lope de Vega. Texto, literatura, cultura, 12, 2006, pp. 141-152.

González Cañal, Rafael, «Temas cervantinos en el teatro de Rojas Zorrilla», Anales cervantinos, 35, 1999, pp. 193-203. 
González Cañal, Rafael, «Francisco de Rojas Zorrilla», en Historia del teatro español, I: De la Edad Media a los Siglos de Oro, coord. Abraham Madroñal y Héctor Urzáiz, Madrid, Gredos, 2003, pp. 1149-1179.

González Cañal, Rafael, «Recepción y trayectoria escénica», en El universo dramático de Rojas Zorrilla, ed. Rafael González Cañal, Valladolid, Universidad de Valladolid, 2015, pp. 139-154.

González Rovira, Javier, La novela bizantina de la Edad de Oro, Madrid, Gredos, 1996.

González de Salas, Jusepe Antonio, Nueva idea de la tragedia antigua, ed. Luis Sánchez Laílla, Kassel, Reichenberger, 2003, 2 vols.

Julio Giménez, Ma Teresa, «Hiperdramatismo en Rojas Zorrilla: ¿innovación o continuidad?», en Francisco de Rojas Zorrilla, poeta dramático. Actas de las XXII Jornadas de Teatro Clásico, ed. Felipe Pedraza, Rafael González y Elena Marcello, Almagro, Universidad de Castilla-La Mancha, 2000, pp. 179-207.

López Martín, Ismael, La anagnórisis en la obra dramática de Lope de Vega, Vigo, Academia del Hispanismo, 2017.

López Pinciano, Alonso, Philosophía antigua poética, ed. José Rico Verdú, Madrid, Turner (Biblioteca Castro), 1998.

Madroñal, Abraham, «Nuevos documentos sobre Rojas Zorrilla y su teatro», Revista de literatura, 69, 137, 2007, pp. 271-295.

Madroñal, Abraham, «Biografía», en El universo dramático de Rojas Zorrilla, ed. Rafael González Cañal, Valladolid, Universidad de Valladolid, 2015, pp. 13-24.

Marcello, Elena E., «Fortuna europea de Rojas Zorrilla», en El universo dramático de Rojas Zorrilla, ed. Rafael González Cañal, Valladolid, Universidad de Valladolid, 2015, pp. 155-173.

Navarro González, Alberto, Cervantes entre el Persiles y el Quijote, Salamanca, Universidad de Salamanca, 1981.

Oleza, Joan, «Los géneros en el teatro de Lope de Vega: el rumor de las diferencias», en Del horror a la risa. Los géneros dramáticos. Homenaje a Christiane FalinLacourt, ed. Ignacio Arellano, Víctor García Ruiz y Marc Vitse, Kassel, Reichenberger, 1994, pp. 235-250.

Pedraza Jiménez, Felipe B., «Los lugares imaginarios en Rojas Zorrilla: Persiles y Sigismunda», en Loca ficta. Los espacios de la maravilla en la Edad Media y Siglo de Oro. Actas del Coloquio Internacional, Pamplona, Universidad de Navarra, abril, 2002, ed. Ignacio Arellano, Pamplona/Madrid/Frankfurt, Universidad de Navarra/Iberoamericana/Vervuert, 2003, pp. 333-348.

Pedraza Jiménez, Felipe B., «Un teatro para los oídos: Los áspides de Cleopatra», en Estudios sobre Rojas Zorrilla, Cuenca, Universidad Castilla-La Mancha, 2007, pp. 201-218. 
Rojas Zorrilla, Francisco de, Persiles y Sigismunda, en Obras completas. Volumen II: Primera parte de comedias, ed. M. a Ángeles García García-Serrano, Cuenca, Universidad Castilla-La Mancha, 2009, pp. 165-298.

Ruiz Montero, Consuelo, La novela griega, Madrid, Síntesis, 2006.

Scaramuzza Vidoni, Mariarosa, «Peripezie di Persiles e Sigismunda sul palcoscenico: I'adattamento teatrale de Rojas Zorrilla», en Atti del Convegno di Studi Napoli, Drammaturgia e spettacolarità nel teatro iberico dei Secoli d'Oro, Nápoles, Edizioni del Paguro, 2000, pp. 203-216.

Vega, Lope de, La doncella Teodor, ed. Julián González-Barrera, Kassel, Reichenberger, 2008.

Vega, Lope de, El peregrino en su patria, ed. Julián González-Barrera, Madrid, Cátedra, 2016.

Yudin, Florence, «Theory and practice of the novela comediesca», Romanische Forschungen, 81, 1969, pp. 585-594. 
